SHS Web of Conferences 24, 02007 (2016)

DOI: $10.1051 /$ shsconf/20162402007

(c) Owned by the authors, published by EDP Sciences, 2016

\title{
Survey on multicultural education situation of schools in Miao nationality areas in south Sichuan province
}

\author{
Tao $\mathrm{Yu}^{1,2} \&$ Yuan $\mathrm{Zhang}^{3 *}$ \\ ${ }^{1}$ Center for Studies of Education and Psychology of Minorities in Southwest China, Southwest University, \\ Chongqing, China \\ ${ }^{2}$ School of Humanities and Management Sciences, Sichuan Medical University, Luzhou, Sichuan, China \\ ${ }^{3}$ Ideological and Political Department, Sichuan Medical University, Luzhou, Sichuan, China
}

\begin{abstract}
In the long run, the school education in scattered and mixed areas not features with multicultural education, but implements a unified school system as well as knowledge contents. And this unified school system does have some negative impacts on the inheritance of the ethnic culture, the academic achievements and the self-identification of the minority children. Multicultural education is essential to motivate the comprehensive development and freedom of people. And the need to implement multicultural education for schools in scattered Miao Region is more urgent than the centered ethnic minority areas. In order to change this situation, we should change the idea of rationalism monism in education.
\end{abstract}

Keywords: multicultural education; scattered ethnic region; Miao ethnic group; value orientation of education

\section{INTRODUCTION}

For a long time, the research on China's multicultural education is generally fixed on some "bright spots", the core areas in minority regions, while the study of multicultural education in scattered and mixed areas seems to have become a "blind spot" to the academic circle. The teacher-and-student structures, school-andcommunity relations as well as local policies in scattered and mixed areas are significantly different with those in core areas. The paths and means in core areas to implement multicultural education are not completely suitable for the school education in scattered and mixed areas. Therefore, for schools in scattered and mixed areas, it is neither a good choice to entirely follow the paths and means in core areas, nor to completely ignore their own responsibility for multicultural education. To this end, the author chooses primary and secondary schools in Hele Township of Miao nationality in Xuyong County in Sichuan as a case to do the survey on multicultural education situation. According to the survey, the author found that the education purposes, curriculum plans and teaching methods are not typical features of multicultural edu-

*Corresponding author: 184627669@qq.com cation but tend to be the unified value orientation.

\section{THE SCHOOL EDUCATION IN SCATTERED AND MIXED AREAS HAS NO FEATURES OF MULTICULTURAL EDUCATION}

2.1 The education homogenization is obvious and the local knowledge becomes aphasiac

According to the survey, the primary and secondary schools in Hele Township of Miao nationality have not effectively followed the basic concepts of multicultural education to implement education policies and teaching programs in line with their local conditions for the purpose of suiting cultural needs of different nationalities, they instead choose to implement a unified school system as well as knowledge contents. For instance, the curricula, all the school courses in Hele Township of Miao nationality are arranged in accordance with currently unified requirements of the state, having no specialized courses manifesting local Miao's culture, even in music, sports and art, which can reflect cultural features. In a word, there are nearly no contents related to Miao's music, traditional sport events as well as arts. Besides, they follows the pace 
with Han nationality in some respects such as the use of teaching materials, examination systems and teaching methods, using standard teaching materials, participating in unified examinations, and nearly using the same teaching methods.

The survey found that the people there have become the real "minority" in the residential places since the scattered and mixed areas are not the core areas, and their cultural traditions, languages, customs and historical knowledge also have been marginalized from local social and cultural structures, constantly surrounded by the strong culture (host culture in the residence places). Taking Hele Township of Miao nationality as an example, the spread breadth and depth of Miao' culture in the main group's (Han nationality) students are far worse than the impact of Han's culture on Miao students, obviously staying disadvantaged. In language, Miao students are required to master and neatly use Han's language, characters and related courses, and also use Han's characters in exams, while Han's students actually do not have such problems. They generally do not understand Miao's language and cultural traditions (such as Lusheng, Miao embroidery, etc.), and are incapable of taking the initiative to communicate with Miao People. The one-way cultural output in school education design makes Miao students get used to accepting Han's culture but lack capacities to output their own culture, resulting in the very obvious cultural convergence and educational homogeneity.

\subsection{Multicultural education becomes formalistic and cut from the community culture, not being really internalized into students' cultural traditions}

The survey shows that there are three main forms for multicultural education carried out in primary and secondary schools in Hele Township of Miao nationality: (1) showing ethnic cultural features in the construction of campus culture. For example, organizing students to learn "Bamboo Dance" instead of radio exercise during long breaks, and posting and hanging ornaments with Miao's cultural features (Lusheng, Ox head, Miao embroidery patterns, etc.); (2) creating extracurricular interest groups related to Miao's culture. Currently, in the four schools of Hele Township of Miao nationality, only the center school has created three groups of extracurricular activity associated with Miao's culture, involving Miao's language, musical instruments of Miao nationality and Lusheng dance. However, according to the survey, although the three interest groups have been set up, there are no full-time instructors, no clear membership structures and no activities till now. That is, these are literally interest groups, not playing any roles in cultural activities on campus. While the other three schools in Hele Township of Miao nationality even have no such formal interest groups; (3) as required by local governments, the schools organize students to participate in gov- ernment-sponsored festivals of Miao, such as Stepping Mountain Festival and Miao's customs festival. Every year, Hele Township of Miao nationality holds various cultural festivals with their own features, and has cultural and art performances at opening and closing ceremonies. The schools are asked to organize students to prepare dancing and singing programs embodying Miao's culture. But the schools face difficulties in organizing such activities due to the policy issues and lack of funds. And both teachers and students are perfunctory in the preparation, not treating these festival celebrations seriously as parts of multicultural education programs.

Overall, the ethnic education activities in the center school nearly have no connection with local Miao community. The construction of campus culture, the interest groups for Miao's culture as well as the celebration activities related to local Miao's festivals, all of these are the school's independent behaviors. Although there are teachers and students from both Miao and Han nationality participating in them, the families of Miao students and local Miao People are not directly involved in the school's ethnic educational activities. These activities deviate away from the daily life and cultural activities of Miao community, belonging to a kind of "official" Miao's cultural educational activity different from local culture.

\section{THE NEGATIVE IMPACT OF UNIFIED EDUCATIONAL VALUE ORIENTATION ON MIAO COMMUNITY'S CULTURE}

\subsection{School education isolates from community education, even clashes with the community education, accelerating the ablation of Miao's culture}

There are no written words of Miao's culture, and most of them are inherited by words of mouth, embedded in daily lives, festivals, weddings and funerals, customs and traditions, and passed down by imparting and learning through generations. Therefore, Miao's culture, under the impact of current dominant culture, is very easy to lose and disappear, although Miao People in scattered and mixed areas are still keeping a clear and strong sense of identity to their local culture to some extent. For instance, in New Year parties, the elders in Miao's families always like to talk about the resplendence and precious value of their ethnic culture, and constantly tell their children to "be polite" and "do things well" " However, compared with core areas, the impact of Han's culture are much stronger and quicker.

First of all, the people in scattered and mixed areas live dispersedly and have worked together with Han People for a long time, suffering a deeper effect of Han's culture. Historically, the entire Miao nationality in Southern Sichuan has been deeply influenced by 
Han's culture. In the 1930s, Mr. Yifu Rui wrote down his preliminary impression on the Miao nationality in Southern Sichuan after doing the investigation, "The group, Yaque Miao, in terms of the material culture, has been completely influenced to some extent by Han nationality in addition to women's clothing, and as for the social organization, they have little significant difference from local farmers. However, they still keep a variety of original manners as well as customs" only in the ceremonies in marriage, funeral and worship ${ }^{[1]}$. In language, all of the adults in Hele Township of Miao nationality are generally able to speak Chinese, while rare Han's adults know about Miao's language.

Second, the schools in scattered and mixed areas attach great importance to the dominant culture, giving lessons in Chinese, and mainly teaching students Han's culture and knowledge (Chinese), modern science (mathematics, biology, physics, chemistry, etc.) as well as social and civic knowledge (life safety, legality, morality, etc.). All of these invisibly force the young generation in Miao nationality to get away from their ethnic culture, making it difficult to be passed down.

Third, school education occupies most of students' time, and all of their learning and life have to go around it. To complete the teaching task of the school, teachers and students have to focus on the study, making students have no spare time to receive family and community education, even no consistent time to learn ethnic culture, such as Lusheng, ancient songs, Miao embroidery, etc. The survey found that children in Miao nationality usually go to school at a very early age. Some children accept pre-school education since the age of three, so they have no opportunities and time to learn Lusheng, Miao embroidery, etc. In Hele Township of Miao nationality, the primary and secondary students are rarely capable of playing Lusheng compared with their forefathers. For the adults in local Miao community, parents fully expect their children to inherit the ethnic culture, and become a qualified Miao People to "be polite" and "do things well". But the current situation of inheriting the traditional culture by teenagers really makes them feel worried but.

\subsection{Heritage of ethnic culture has been misplaced}

The survey found that although local schools intend to allow students to have more opportunities to experience and understand Miao's culture, they do not effectively investigate the culture in local Miao community in the process of trying to carry out ethnic cultural educational activities, but mechanically introduce cultural traditions from other Miao groups which actually do not suit them, leading to the dislocated heritage of ethnic culture. The first we should care about is the dislocated heritage in existing culture. In Hele Township of Miao nationality, Lusheng and cow leather drums are only used in funeral and sacrifice ceremonies, but now they appear in the occasions such as Miao's cultural festivals, various celebrations and entertainments held by local governments. In the meantime, schools organizing students to play music using Lusheng is just for the purpose of festival ceremonies. It only involves melodies and dance moves, making Lusheng lost its function to transfer Miao's knowledge and moral culture through funeral and sacrifice rites. Therefore, it's not surprised that Lusheng lost its status as a representative in traditional Miao's culture. The second we should worry about is to mechanically introduce Miao's culture from other areas. For instance, the "Bamboo Dance" which has been adopted as the physical exercise during long break time by the center school in Hele Township. There is a big difference, both physically and spiritually, from the earlier "Bamboo Dance" 2 existed in local community.

\section{THE NEGATIVE IMPACT OF UNIFIED EDUCATIONAL VALUE ORIENTATION ON MIAO STUDENTS}

The school education under the guidance of monistic theory not only affects the heritage of Miao community's culture, but also has a bad influence on Miao students. In the survey, we found that Miao students in scattered and mixed areas of Miao nationality in Southern Sichuan generally have two problems. One is the worse educational background of Miao students. When they enter into the dominant society, they get fewer opportunities to go in upper classes and cannot obtain recognition by the dominant society. After graduating from junior high school or high school, they have to work outside or go back to farm, getting no more chances for social promotion through school education. The other is, since the students have not mastered their ethnic traditional culture in growing years and lacked ethnic self-identity, it is hard for them to get recognized by other ethnic members after returning home, eventually becoming the "cultural marginalized people".

\subsection{Miao students face learning communication problems, which directly affect their interest and confidence in learning}

To the minority students in scattered and mixed areas, the language, culture and knowledge they receive after entering school are completely different from what they have learned in childhood. The preschoolers in Hele Township learn Miao's language since they were born, and they usually speak Miao's language in daily life. Thus they know little about Chinese. However, to boost the merging of Miao students into the dominant culture, schools give lessons in Chinese and require teachers and students to speak Mandarin or Sichuan dialect for communication during break periods. 
Therefore, the school-age children have to face a problem since entering school, namely, mastering a new language in a short time. It directly affects students' interest and confidence in learning. Compared with their classmates who come from Han group, they are easier to be self-abased and more prone to be weary of learning, which are obviously not helpful for them to achieve good results in examinations, entrance exams and other competitions. In the long run, after entering the society, Miao students with worse educational background are generally not easy to improve their status through excellent academic performance and get recognition from the dominant society.

\subsection{Miao students are prone to suffer cultural identity problems}

In school education, the unified value orientation makes Miao students can't get access to the information related to their own culture, such as Miao's language, ethnic dances, customs, taboos, ethnic festivals and lack opportunities to acquire their own cultural traditions and histories, resulting in the gap between Miao students and their group. Also, it makes them become "outsiders" after growing up and unable to internalize group's culture, history and traditions as parts of their identity. In recent decades, although Miao groups have established good relations with Han community through long-term exchanges, and the people in Hele Township of Miao nationality have gotten accustomed to communicating with local Han People in a kind of Sichuan dialect (an entering tone spoken in a small independent area in southern $\mathrm{Si}$ chuan) free of obstacles, Miao's adults still feel a sense of isolation from Han People. In the meantime, the adults in Hele Township of Miao nationality are easier to accept those Han People who can speak simple Miao's language, considering them as "insiders" and more willing to carry out in-depth conversations and exchanges with them. Obviously, their senses of ethnic identity are very distinct. However, the Miao students accepting school education are more interested in modern civilization and dominant culture (such as computer games, mobile games, popular music, etc.), not expecting to learn Lusheng and Miao's language as well as wearing Miao's clothes.

According to the survey, due to historical reasons, the impact of it still remains even though the discrimination of local people against Miao groups has disappeared, making Miao People in scattered and mixed areas have less sense of ethnic pride and self-acceptance. For example, the mixed marriage between Han and Miao nationalities in the 556 families in Fuxing Village in Hele Township of Miao nationality, there are only six families choosing to marry with Han People, accounting for $1 \%$ in the total number of the families in this village. Despite that the state has special care policies to the minority, two thirds of the six families preferred to choose "Han nationality" for their children ${ }^{3}$. As for the language, in southern Sichuan, the word "Miao" means negative and usually stands for a strange, brutal and violent personality (for example, if someone is considered as "Miao", he or she is deemed to be strange and hard to get along with.). To this end, local Miao People are used to calling "Miao nationality" as "the ethnic", and calling "speaking Miao's language" as "speaking a kind of ethnic dialect". Besides, they are quite disgusted to be called "Miao Zi" (negative words) by other nationalities. Due to the lack of multicultural education, Miao students can't correctly understand their own culture and its relationships with other ethnic cultures. It is one of the reasons why they lack the sense of identity and belonging to their own group and ethnic culture, and also why they can't form a correct sense of identity as an ethnic member. A growing number of Miao's teenagers can't establish an effective sense of ethnic recognition and identity. On one hand, they know there is a deep ethnic cultural imprint on them, making them different from local Han People. On the other hand, they can't accept, respect and love Miao's culture from their hearts. Since they have not known well about their own culture, they are considered as "outsiders" by other members of the group, living in an awkward "cultural marginalized" situation.

\section{ENLIGHTENMENT OF MULTICULTURAL EDUCATION ON SCHOOLS IN SCATTERED AND MIXED AREAS}

\subsection{Multicultural education is the essential demand for individuals to achieve free and comprehensive development}

Currently, multicultural education in Western countries has already evolved into an effectively national education movement and a necessary mean to promote the healthy development of the multicultural society. For China, it is important to learn ideas and means from western countries combining with the education situations in minority areas to achieve the multicultural education. It has been generally agreed that multiculturalism is human's essential demand, and also is the prerequisite for human's independent life, self-determination and self-selection. Further, the purpose of multicultural education is consistent with the essential demand of human's free and comprehensive development, which is the basic idea supposed to be implemented in education. The real multicultural education is the premise for people to live a good, self-determining and prosperous life, and helps people realize their equal status and rights for free development in the country and society. While for scattered and mixed areas of Miao nationality in southern Sichuan, first of all, cultivating the capacity of students' self-selection and self-determination is the primary task of school education, for which the multicultural 
education being implemented by schools must be open, recognizing and clarifying the objectivity of co-existence of local Han's culture and Miao's culture, recognizing the equal status of different cultures and the significance to the development of modern society brought by mutual influence and promotion of different cultures, and offering students necessary and real options for self-selection and self-determination. Second, the content of multicultural education should be multicultural in some ways. That is, the multicultural education in schools must provide chances to the students to experience and understand different cultures that exist in local areas, and respect the unique values of different ethnic groups and cultural groups in the ways of life, value orientation and behavior patterns represented by the multi ethnic cultures. And the objects of multicultural education not only include Miao students, but also Han's and other ethnic students.

\subsection{Scattered and mixed areas are more needed to implement multicultural education concepts than core areas}

First, unlike the schools in core areas where most of the students are the minorities, the number of Miao students in the schools in Hele Township of Miao nationality is nearly the same with the number of Han's students. Thus it is necessary to consider both Miao students and Han's in terms of teaching materials and ethnic cultural courses. Second, according to the survey, due to the lack of ethnic identity and the experience of long-term sufferings of discrimination mentioned above, Miao students are not willing to independently learn and show Miao's culture in front of Han's students, such as playing Lusheng, learning Miao's dance and wearing Miao's clothes, making students lack motivation in schools' multicultural education activities. Third, being affected by the dominant culture, Miao students and their families are more inclined to study for entrance exams and future employments. It can be said that they are not very concerned about the ethnic culture taught in school. But, on the other side, Miao People in scattered and mixed areas still have a strong and clear sense of their ethnic culture identity, and very much hope that their children can inherit the ethnic culture and "be polite" and "do things well" in the name of a qualified Miao People to. Therefore, the situation in scattered and mixed areas is more in line with the essential requirements of multiculturalism and multicultural education, and they are more needed to implement the basic concepts of multicultural education.

5.3 The lack of features of multicultural education in school education at scattered and mixed areas is fundamental because of the impact of rationalistic monism

According to the survey of fieldwork, we can see that the school education in scattered and mixed areas of Miao nationality in southern Sichuan can't bear the primary responsibility of multicultural education, and the ethnic education activities are mostly formalistic or perfunctory. Besides, those activities have been separated for a long time from the ethnic community life, even clashed with it. For all of these, we can find out many reasons such as the lack of policies, schools' weak consciousness for multicultural education, or the neglect of multicultural education by Miao students and their family. However, from a more deeply aspect, all of the phenomena neglecting the multicultural education are caused by a fundamentally thinking mode, namely the rationalistic monism which underlies the educational value orientation of schools in scattered and mixed areas of Miao nationality in southern Sichuan, and it has become the ultimate guiding idea that determines the educational methods, tools and purposes. In other words, for schools, multicultural education is just the surface, but the educational thoughts based on monistic theory actually play a fundamental role in local education system. For students, it is still a long way to cultivate the inclusive, open-minded and independent outlook on value. Currently, the educational idea based on monism is continued to be implemented, and its adverse consequences are increasingly prominent, even aggravated, producing a seriously adverse effect both on the cultural heritage of Miao community and the personal growth of Miao students in scattered and mixed areas in Southern Sichuan.

\section{ACKNOWLEDGEMENT}

This project is supported by the Center for Rural Childhood Education Research.

\section{NOTES}

1. The people in Hele Township of Miao nationality generally call the sacrifice rites like "uat bles (A kind of superstitious activity in funeral ceremonies asking monks or Taoists to recite scriptures to save the dead from misery)" and "uat beuk" as "do things". "Do things well" means to understand various rites in funeral ceremonies, and it also means being able to participate in the specific matters such as playing Lusheng and saying sacrifice words in sacrifice rites. Such kind of people are respected by family.

2. According to X Li's words of mouth, a villager from Miao nationality, the "Bamboo Dance" in Hele Township of Miao nationality originated in the process of "giving presents" in marriage and funeral ceremonies. In the marriage and funeral ceremonies, the guests brought some presents, such as corns, rice, wine, etc., and the host asked a specific person (called "internal director") to be responsible for handling the 


\section{SHS Web of Conferences}

presents. In the process of "giving presents", the guest who gave presents and the internal director sang and responded to each other, occasionally lasting for an hour. Sometimes, there were lots of guests, so they had to wait for a long time outside the house to give the present. Meanwhile, their presents would always block the way so that people had to jump across the bamboo poles (being used to place the presents). Gradually, it evolved into "Bamboo Dance" along with the melodies of Lusheng. "Bamboo Dance" was to lay the bamboo or bamboo poles parallel on the ground, and people walked and danced, jumping across the bamboo or bamboo poles. It is obviously different from the modern "Bamboo Dance" which needs someone to lift, down, separate and close the bamboo, and in the meantime dancers jump and move along with the opening and closing rhythm. Li once has seen the old "Bamboo Dance" in the participation of Stepping Mountain Festival in childhood (about 40 years ago), but now nobody can dance. Dictation time: September 17, 2014.

3. The statistic data come from "Regular Residence
Information Table of Fuxing Village in Hele Township of Miao Nationality". Deadline: May 21, 2014.

\section{REFERENCES}

[1] Yifu Rui \& Donggui Guan. 1941. The Information about Marriage and Funeral Rites in Yaque Miao Nationality in Southern Sichuan. Taipei, Taiwan: the Twenty-three of A-Type of Single Publication by History and Language Institution of Chinese Academia. pp.3.

[2] Berlin Isaiah. 2009. Crooked Timber of Humanity. Translated by Xiukun Yue. Nanjing: Yilin Press.

[3] James A Banks. 1994. An Introduction to Multicultural Education. Boston: Allyn and Bacon.

[4] Fang Liu. 2009. The Context of cultural factors in changes in scattered and mixed areas of minorities -survey and analysis of Jiancao Gaoshan Miao Nationality in Xuyong County in Sichuan by Ye Tian. Journal of Southwest University for Nationalities (Humanities and Social Sciences Edition), (10).

[5] Yuan Zhang \& Tao Yu. 2013. Analysis of the minority on safeguarding their rights through the movie Warriors of the Rainbow: Seediq Bale. Guizhou Ethnic Studies. 